\title{
LCA-AZT Conjugate Anti-Cancer invitro Activity
}

\author{
Taipeng Shen ${ }^{1}$, Jessie Cook ${ }^{2}$, Yuan Ren ${ }^{1}$, Lu Zhang ${ }^{1}$, Zhuzhong Cheng ${ }^{1}$, Jinyi Lang ${ }^{*}$ and Hengguang Li1, 2* \\ ${ }^{1}$ Sichuan Cancer Hospital \& Institute, Sichuan Cancer Center, School of Medicine, University of Electronic Science and Technology of China, Radiation
} Oncology Key Laboratory Of Sichuan Province, Chengdu, Sichuan 610041, China

${ }^{2}$ Department of Chemistry, Physics \& Material Science, Fayetteville State University, Fayetteville, USA

Submission: January 22, 2020; Published: February 21, 2020

*Corresponding author: Hengguang Li and Jinyi Lang, Department of Chemistry, Physics \& Material Science, Fayetteville State University, Fayetteville, NC 28301, USA

\begin{abstract}
Pseudo nucleoside or short pseudo aptamer and telomerase have been selected as novel ligands and receptors in our effort to discover new anti-cancer reagents. We proposed that lithocholic acid (LCA) could be able to play the role of a vehicle to transport major therapeutic moiety into cell membrane through oral administration, like cholic acid delivering fatty acids, peptides in gastrointestinal track, but it's more hydrophobic. Zidovudine or azidothymidine (AZT) was used as targeting head or/and therapeutic reagent aiming reverse transcriptase that plays central role of cancer cell telomere repairing. Telomerase is a reverse transcriptase, the major TERT, or hTERT in humans is a catalytic subunit of the entire enzyme.

Even though both LCA and AZT have anticancer activities respectively, the conjugate of LCA-AZT was designed as our initial pseudo short aptamer inhibitor of cancer telomerase to verify our hypothetic concept that pseudo short aptamers targeting cancer telomerase are able to shut down the cancer cell growth, and cause the cells eventually senescence and mortality. As a consequence, two lung cancer cell lines and two colorectal cancer cell lines were treated by the conjugate, except lung cancer cell H1299, the efficacy of the conjugate was better than the parent compounds apparently.

It conformed and proofed also the docking predictions via the molecular computational simulation. The all cancer cells used by a CCK-8 assay appeared apoptosis in the range of $56 \mu \mathrm{M}-90 \mu \mathrm{M}$ IC50 after exposure to the LCA-AZT conjugate. The effectiveness of the conjugate was also time dependent, because the telomerase is a kind of reverse transcriptase, the mechanism would be like the inhibition of reverse transcriptase in HIV virus, the inhibition of telomere repairing toward cell death would be time consumable.
\end{abstract}

Keywords: Essential Oils; MRSA; M. Tuberculosis; Antibacterial Activity; Drug-Resistant Microbes

Abbreviations: LCA: Lithocholic Acid; AZT: Zidovudine or Azidothymidine; TERT or hTERT: In Humans-Telomerase Reverse Transcriptase; DCMDichloromethane; DMAP-4-Dimethylaminopyridine; TEA: Triethylamine; DCC: 1,3-Dicycloheylcarbodiimide; THF: Tetrahydrofuran; DMF: N, N-Dimethylformamide; CA: Cholic Acid; DCM: Dichloromethane

\section{Introduction}

As we know AZT, an anti-HIV reagent, was used as a pseudo nucleoside that was supposed to be able to target telomerase [1] that is also a reverse transcriptase. Azidothymidine induces apoptosis and inhibits cell growth and telomerase activity of human parathyroid cancer cells in culture suggesting that AZT can be proposed as a potential antiparathyroid cancer agent [2]. On the other hand, since preliminary in vitro research suggests that lithocholic acid (LCA) selectively kills neuroblastoma cells, while sparing normal neuronal cells. It is cytotoxic to numerous other malignant cell types at physiologically relevant concentrations [3]. We proposed that lithocholic acid (LCA) could be able to play the role of a vehicle to transport major therapeutic moiety into cell membrane like cholic acid delivering fatty acids, peptides [4], while the zidovudine or azidothymidine (AZT) was used as targeting head or/and therapeutic reagent that aims reverse transcriptase that plays central role of cancer cell telomere repair.

In addition, since LCA (and LCA acetate and LCA propionate) is a component of bile acids and in charge of nutrients transporting with higher bioavailability and lower toxicity, it can, on the other hand, activate the vitamin $D$ receptor without raising calcium levels as much as vitamin D itself [5]. LCA was also shown to have antiaging effects in a yeast study [6]. It was known that the bile acid 
accumulates in the inner and outer mitochondrial membranes, altering the mitochondria's lipid composition by promoting or inhibiting various enzymes [7].Telomerase as target for cancer treatment has great potential [8]. It has been reported that AZT synergistically interacts with other treatment modalities, including chemotherapy agents $[9,10]$. Therefore, AZT and its derivatives may be a novel strategy for the treatment of cancers with broad spectrum, including those derived from the esophagus, human parathyroid. However, the mechanism by which AZT inhibits cell growth and arrests cell cycle progression in more other cancers requires further investigation. In this report, two long cancer celllines and two colorectal cell-lines were selected for trail because of clinic high incidence in China.Pseudo aptamers are the derivatives of aptamers [11], known as "chemical antibodies". They behave not only as small molecules, but also as large biological compounds. Although additional research is being conducted, there are multiple concerns about the applications of such aptamers, specifically their administrations, degradation, excretion, stability when subjected to drug developments. This leads to searching for a way to optimize the aptamer by structural modification to ensure its activities and bio-availabilities, targeting the defined molecules efficiently. The objective of this project was to build a series of pseudo aptamers that target the telomerase in cancer cells based on rational design to improve the activity, toxicity, delivery, metabolisms, and bio-feasibilities. The first step was to manipulate a normal aptamer into an intense spiral helix that was hypothesized computationally to replace the diphosphate linker by a triazole or sulphonyl groups. Azide functional group provides an advantage of click cyclization to form triazole linker to realize the chain elongation [12]. In this report, LCA-AZT conjugate was designed for primary evaluation by taken the advantages of conjugation medicines via ester bond and introducing azide group for future modification [13].

\section{Discussion}

\section{Design}

In the design of docking simulation, because that the receptor Tribolium castaneum telomerase catalytic subunit, TERT, has large catalytic cavity where the telomere is repaired. It was found that LAC-AZT conjugate can be embodied fully inside, thus there are many conformational structures interacting between the smaller ligand and the binding sites in the large cavity. Over nine highest and similar binding affinities and the conformations were selected for comparisons. The docking simulations of LCA, AZT and LCA-AZT were performed respectively, the predictions were listed below as figure 2. As the result, the binding affinities of the parent compounds are lower than the conjugates about 2.0 to $3.0 \mathrm{kcal} / \mathrm{mole}$, which was agreement with the cell culture assessments. The best nine conformations binding predictions of the three compounds were picked out, in which the LCA moiety was observed to insert into the hydrophobic pocket deeply, suggesting that LCA could impact entire ligand's binding affinity (Figures 1 \& 2).
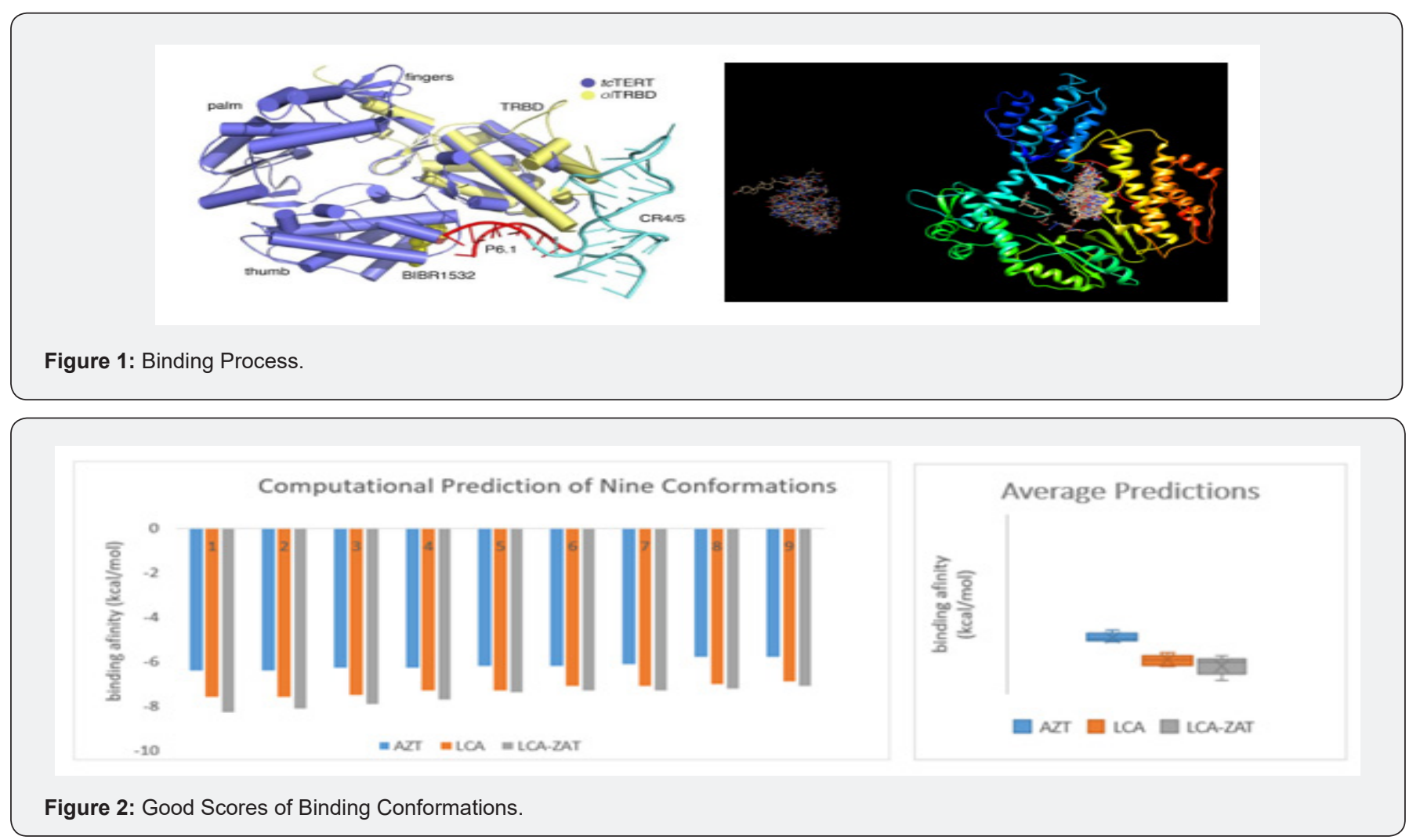


\section{Synthesis}

The esterification between LCA and AZT was slower, and equilibrated in three days, the reaction gave about 30\%-60\% maximal yield after purification. Several different conditions were investigated, particularly solvents, catalysts. The esterification seems easy; however, it was found that it is difficulty to improve the yield neither directly coupled by DCC nor by active ester of HOSu approach in one pot reaction. Because of selectivity and solubility, the intramolecular coupling of LCA had to be avoided, we took the experience of previous synthesizing cholic acid conjugate [1], similar condition was tried. Even though there are multiple hydroxyl on the fused rings of cholic acid, the selectivity was excellent, the results were displayed as table 1 below. DMAP was always better than TEA. The impact of HOSu seemed not significant. The relative lower yields might be owing to the DCC intermediate formation. The active ester separation could be the solution, 1, 1'-carboxyldiimidazole (CDI) will be also good activation reagent, if isolated, it will take two steps (Figure 3).

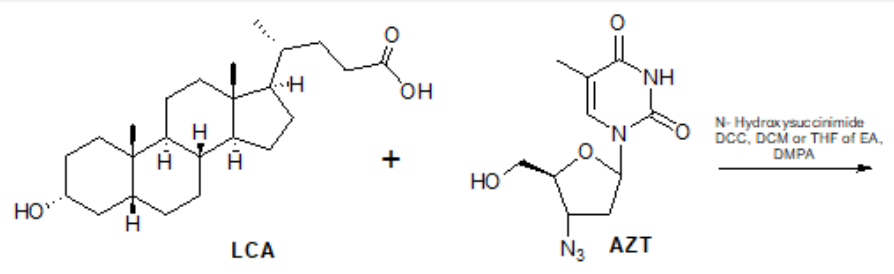<smiles>CCCCCC(C)(C)C(C)(C)C</smiles>

Reagents and condition: LCA, AZT, r.t. (r.t.); N- Hydroxysuccinimide, DCC, DCM, DMPA or TEA, r.t.

Figure 3: Chemically Conjugating.

\section{Primary Evaluation}

LCA was used as a vehicle to transport into cell membrane except its activity. After exposure to the LCA-AZT conjugate, three out of four lung and colorectal cancer cells conducted by CCK-8 assay were induced apoptosis in the range of $\mathrm{IC}_{50} 56 \mu \mathrm{M}-$ $68 \mu \mathrm{M}$. Besides, the effectiveness of the conjugate was also time dependent, which means that the mechanism could be deferent from cytotoxic agents in chemotherapy. Because a telomerase is a kind of retro transcriptase, the mechanism would be like the inhibition of reverse transcriptase in HIV virus, it removes the protection of the telomere, rather than kills malignant cell directly, causing cell apoptosis slower. By developing a solution phase synthesis, we can create an intensive helix designed triazole, and sulfonyl linked pseudo short aptamer. The aptamer is theorized to be structurally sound and appropriate to target the cancer telomerases causing the cancer cells to deactivate their growth rate, ultimately cause the cells to cease life completely. In practice, a CCK-8 assay was utilized to measure cell proliferation inhibition after the treatment with different concentration LCA, AZT and LCA-AZT for $72 \mathrm{~h}(\mathrm{n}=4)$ (Figures 4 \& 5).

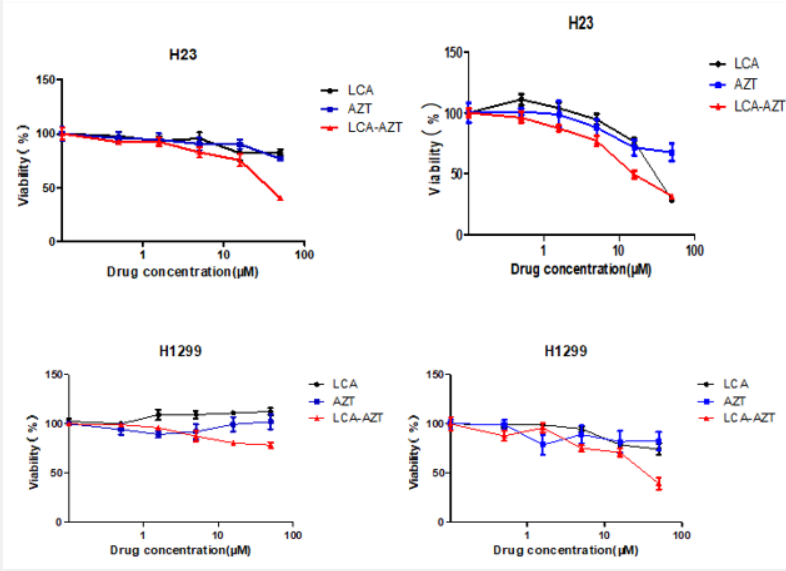

Figure 4: Repeatable inhibition tests on lung cancer cell lines H23 and H1299 proliferations treated by LCA, AZT and LCA-AZT. 

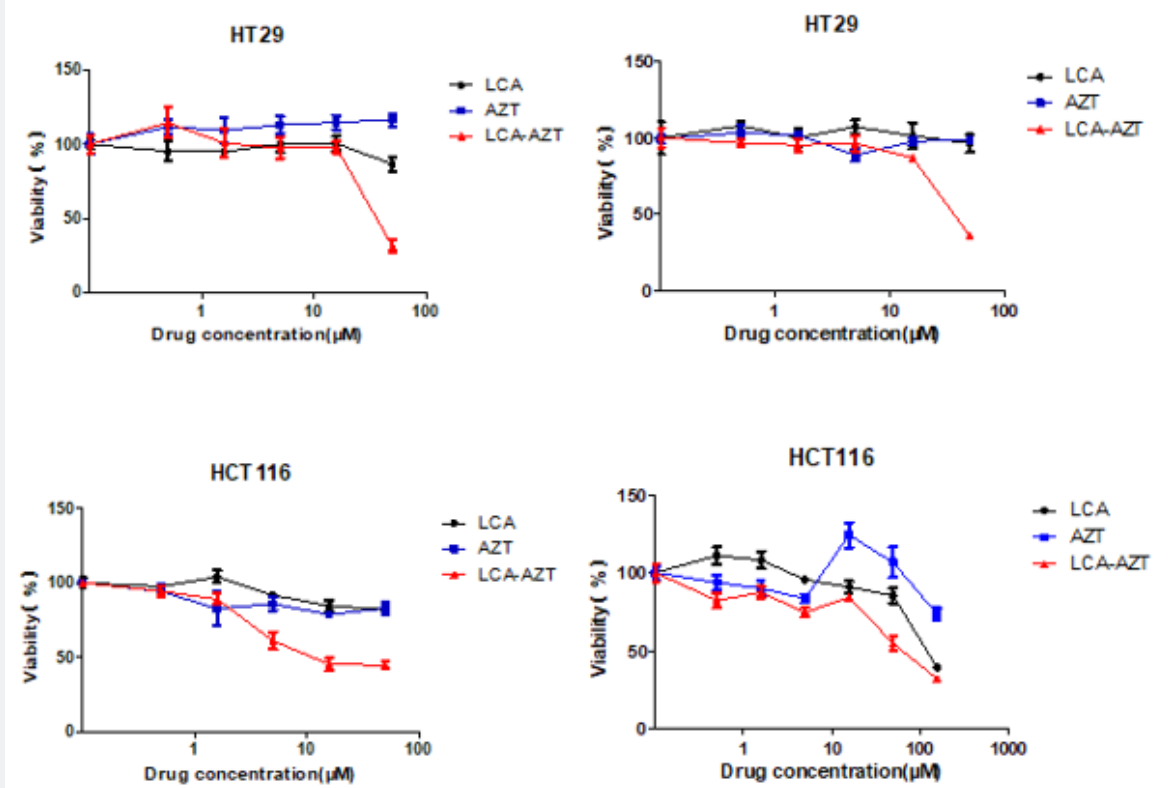

Figure 5: Repeatable tests on colorectal cancer cell lines HT29 and HCT116 proliferations treated by LCA, AZT and LCA-AZT.

\section{Experiment}

Cell-lines ware from the laboratory of the Institute of Sichuan cancer research, China. Melting points were determined on a MelTemp-II melting point apparatus and are reported as uncorrected values. NMR data were recorded on a Jeol 400 spectrometer and the chemical shifts $(\delta)$ are reported in parts per million (ppm). Coupling constants (J) are reported in Hertz. The abbreviations used are as follows: s (singlet), d (doublet), t (triplet), q (quartet), m (multiplet), dd (double doublet), pt (pseudo triplet), brs (broad singlet). Mass spectra were either recorded on an ES-API mass spectrometer or obtained from the Department of Chemistry Mass Spectrometry facility at the Sichuan University. Standard workup procedure after the reactions, where specified, was to wash the reaction mixture with equal volume of saturated sodium bicarbonate solution and brine with subsequent drying of the organic layer (sodium sulfate or magnesium sulfate). All the chemicals were purchased from VWR, Aldrich Chemical Co., ACROS ORGANICS, Fisher Scientific, Sigma Chemicals, or Lancaster Synthesis. Chromatography refers to flash chromatography conducted on Kieselgel 60 230-400 mesh (E. Merck, Darmstadt) using the indicated solvents. Thinlayer chromatography (TLC) was performed on precoated Merck silica gel $60 \mathrm{~F}_{254}$ plates.

\section{Docking}

Target protein was from PDB bank, 3du5 or Tribolium castaneum telomerase catalytic subunit, TERT, is the major subunit of the telomerase where the telomere is repaired. PyRx and Chima virtual screen program Vina AutoDocking were used for computational simulation. The ligand molecules are built with Chem3D Ultra 10, the conformation energies were than minimized by MM2 and Mechanics, step interval $2.0 \mathrm{fs}$, frame interval $10 \mathrm{fs}$, terminate aster 10000 steps, heating/cooling reate $1.000 \mathrm{Kcal} /$ atom/ps, target temperature $300 \mathrm{~K}$. The energy minimized structures were saved as pdb extension format. UCSF Chimera and PyRx Virtual Screening Tool were then used for docking simulation. Over twenty conformations of ligand were automatically interacted in the pocket of the receptor 3du5, Tribolium castaneum telomerase catalytic subunit, TERT, which bound to putative RNA template and telomeric DNA. Nine similar active conformations were taken as the predicted results, binding positions were not fixed on some residues. Autogrid Dimensions: Grid Center X: 70.0458, Y: -31.058, Z: 1.7880, Number of Points X: 50, Y: 50, Z: 50; Spacing: $0.3750(\AA)$. Nine of multi-conformations dominate the active binding structures and would be compared with cell assay consequences.

\section{Chemical Conjugation}

To a $50 \mathrm{~mL}$ two-necked flask under nitrogen protection and magnetic stirring bar was added LCA (1.5 eq.), AZT (1.0 eq.), solvent $15 \mathrm{~mL}$ (such as tetrahydrofuran THF, or Ethyl acetate EA, or dichloromethane DCM) at the room temperature, followed by adding DCC (1.2 eq.) in the same solvent ( $5 \mathrm{~mL}$ ), and N-hydroxy succinimide HOSu or NHS (1.0 eq), and dimethylamine pyridine DMAP ( 0.1 eq.) in the same solvent $1 \mathrm{~mL}$ or trimethylamine TEA (2.0 eq.) dropwise. The mixture was stirred at room temperature for $3 \mathrm{~d}$, during the reaction, a white precipitate of Dicyclohexylurea DCU gradually formed. TLC monitored the progress of the reaction, ethyl acetate was the developing mobile phase, the UV color development is visible. After 3 days of reaction, the TLC 
showed the reaction stopped. The mixture was filtered to remove the white precipitate, and the filtrate was washed by water, saturated $\mathrm{NaCl}$ respectively, and dried over anhydrous $\mathrm{N}_{2} \mathrm{SO}_{4}$, after concentrated a white crude solid was given. The crude product was re-dissolved in $3 \mathrm{~mL}$ of ethyl acetated and subjected to purification by flash column chromatography of silica gel, eluted by hexane / EA proportion from100:0 to 0:100.

((3S,5R)-3-azido-tetrahydro-5-(3,4-dihydro-5 methyl-2,4-dioxopyrimidin-1(2H)-yl) furan-2-yl) methyl 4-(hexadecahydro-3-hydroxy-10,13-dimethyl1H-cyclopenta[a]phenanthren-17-yl) pentanoate

The reaction of AZT (1.5 eq.) with LCA (1.0 eq.) yielded compound (30-60\%) as a white solid. mp $127-130{ }^{\circ} \mathrm{C}$; $1 \mathrm{H}$ NMR (400 MHz, CD3OD) $\delta 9.82$ (s, HN, 1H), 7.82 (s, NHC=C, 1H), 6.02 $(\mathrm{t}, \mathrm{CCHON}, \mathrm{J}=6.0 \mathrm{~Hz}, 1 \mathrm{H}), 5.21(\mathrm{~m}, \mathrm{OHCN}, 1 \mathrm{H}), 5.12\left(\mathrm{~m}, \mathrm{CH}_{2} \mathrm{CO}\right.$, 2H), $3.35(\mathrm{~m}, \mathrm{HOCHC}, 1 \mathrm{H}), 2.59\left(\mathrm{~m}, \mathrm{CCH}_{2} \mathrm{C}, 4 \mathrm{H}\right), 1.98(\mathrm{~s}, 3 \mathrm{H}$, $\left.\mathrm{C}=\mathrm{CH}_{3}\right), 2.00-1.80\left(\mathrm{~m}, \mathrm{CCH}_{2} \mathrm{C}, 10 \mathrm{H}\right), 1.70-1.45(\mathrm{~m}, \mathrm{CH}, 8 \mathrm{H}), 1.45-$ $1.35(\mathrm{~m}, \mathrm{CH}, 10 \mathrm{H}), 1.22\left(\mathrm{~s}, \mathrm{CCH}_{3}, 6 \mathrm{H}\right), 1.10\left(\mathrm{~s}, \mathrm{CCH}_{3}, 3 \mathrm{H}\right) ;{ }^{13} \mathrm{C} \mathrm{NMR}$ (150 MHz, CD3OD) $\delta 178.6,166.3,158.9,138.1,111.6,87.1,86.6$, $73.5,60.4,59.7,58.8,52.7,51.1,47.2,43.5,42.3,41.7,39.4,37.6$, 36.8, 35.2, 34.4, 33.7, 32.2, 31.8, 29.3, 28.6, 27.7, 22.3, 20.4, 19.7, $16.9,16.1,15.4$; ES-API (-) m/z cal cd for $\mathrm{C}_{34} \mathrm{H}_{51} \mathrm{~N}_{5} \mathrm{O}_{6} 624.3$ [M-H]-, 660.2 [M-Cl]- found 624.2, 660.3.

\section{Cell Line}

Colorectal cancer cell line HCT 116 and HT 29, lung cancer cell line H 23 and H 1299 were from the laboratory of the Institute of Sichuan cancer hospital, China. HCT 116 and HT 29 cells were incubated in DMEM/F-12 (1:1) supplemented with $100 \mathrm{U} / \mathrm{ml}$ streptomycin/penicillin and $10 \%$ fetal bovine serum. The cells were incubated at $37^{\circ} \mathrm{C}$ in the presence of $5 \% \mathrm{CO}_{2}$ The cells at the phase of logarithmic growth were used for later experiments. HCT 23 and H 1299 cells were cultured in RPMI 1640 supplemented with $100 \mathrm{U} / \mathrm{ml}$ streptomycin/penicillin and 10\% fetal bovine serum. The cells were incubated at $37^{\circ} \mathrm{C}$ in the presence of $5 \%$ $\mathrm{CO}_{2}$. The cells at the phase of logarithmic growth were used for later experiments.

\section{CCK-8 Assay}

Suppression of all cell lines proliferation were assessed using the CCK-8 Kits following the manufacturer's instructions. The cells viability was expressed as the percentages of viable cells comparing with total untreated cells control. All the cells were seeded in 96-well plates $\left(4 \times 10^{3}\right.$ cells per well, $\left.100 \mu \mathrm{l}\right)$, and incubated in culture medium with $0.5,1.58,5,15.8,50$ and $158 \mu \mathrm{M}$ LCA, AZT and LCA-AZT for $72 \mathrm{~h}$. As a control, HCT116 cells were additionally treated with DMEM alone. CCK-8 solution (10 $\mu \mathrm{l})$ was added to each well of the plate directly and incubated for $2 \mathrm{~h}$ in a $\mathrm{CO} 2$ incubator. The absorbance was measured at $450 \mathrm{~nm}$ using a microplate reader. Suppressions of H 23, HT 29 and H 1299 cell proliferation were assessed by the same method.

\section{Cell Culture Test}

Cell proliferation was inhibited following treatment with 0.5 , 1.58, 5, 15.8, 50 and $158 \mu \mathrm{M}$ LCA, AZT and LCA-AZT for $72 \mathrm{~h}$, as determined by a CCK- 8 assay. The inhibitory effect of LCA-AZT for H23, HT29 and HCT116 cells were time- and dose-dependent (Figure 1) while a small inhibition for H1299 cells were detected. However, treatment with $1.58 \mu \mathrm{M}$ of LCA-AZT did not have a significant inhibitory effect on cells. All cells were insensitive to the anticancer effects of AZT within the experimental concentration range. There were literatures reported that AZT inhibited the growth of many tumor cell lines, covering a wide range of concentrations. The IC50 varied from 0.25 to $1.35 \mathrm{mM}$ for the cancer cell lines and no correlation of IC50 with the rate of cell growth was noted. LCA and AZT conjugated via ester bond improves the anticancer effect but reduced its water solubility.

\section{Conclusion}

In conclusion, the all cancer cells used by a CCK-8 assay appeared apoptosis in the range of $56 \mu \mathrm{M}-90 \mu \mathrm{M}$ IC50 after exposure to the LCA-AZT conjugate. The effectiveness of the conjugate was also time dependent, Even the telomerase is a kind of reverse transcriptase, the mechanism would be like the inhibition of reverse transcriptase in HIV virus. This mechanism of inhibition of telomere repairing toward cell death would be time consumable. Computational predictions and the cells assessments are agreement. AZT-derived conjugates and potent of 1,2,3-triazoles short pseudo aptamers may provide remarkable nucleoside even nucleotide candidates for the future anti-cancer drug development.

\section{Acknowledgement}

This research has been supported by Sichuan Cancer Hospital \& Institute, Sichuan Cancer Center, School of Medicine, University of Electronic Science and Technology of China, Radiation Oncology Key Laboratory of Sichuan Province.

\section{References}

1. Haoli Wang, Jianwen Zhou, Qiong He, Yu Dong, Yanhui Liu (2017) Azidothymidine inhibits cell growth and telomerase activity and induces DNA damage in human esophageal cancer. Molecular Medicine Reports 15: 4055-4060.

2. Alberto Falchetti, Alessandro Franchi, Cesare Bordi, Carmelo Mavilia, Laura Masi, et al. (2005) Azidothymidine Induces Apoptosis and Inhibits Cell Growth and Telomerase Activity of Human Parathyroid Cancer Cells in Culture. Journal of bone and mineral research 20: 3.

3. Goldberg AA, Beach A, Davies GF, Harkness TA, Leblanc A, et al. (2011) Lithocholic bile acid selectively kills neuroblastoma cells, while sparing normal neuronal cells. Oncotarget 2(10): 761-782.

4. Hengguang Li, Haijing Song, Svein Oie, Robbert D Lu (2017) Synthesis of cholic acid-peptide Conjugates with a negatively charged ester linkage for oral delivery. JOM Medicinal Chemistry 7(2): 769-776.

5. Ishizawa M, Matsunawa M, Adachi R, Uno S, Ikeda K, et al. (2008) "Lithocholic acid derivatives act as selective vitamin D receptor 
modulators without inducing hypercalcemia". The Journal of Lipid Research 49 (4): 763-772.

6. Goldberg AA, Richard VR, Kyryakov P, Bourque SD, Beach A, et al (2010) Chemical genetic screen identifies lithocholic acid as an antiaging compound that extends yeast chronological life span in a TORindependent manner, by modulating housekeeping longevity assurance processes. Aging, 2(7): 393- 414.

7. Beach A, Richard V R, Leonov A, Burstein M T, Bourque S D, et al. (2013) Mitochondrial membrane lipidome defines yeast longevity. Aging 5 : 551-574.

8. Chen Z, Corey DR (2003) Telomerase inhibitors: A new option for chemotherapy. Adv Cancer Res 87: 31-58.

9. Chen C, Zhang Y, Wang Y, Huang D, Xi Y, et al. (2011) Synergic effect of 3' azido 3 ' deoxythymidine and arsenic trioxide in suppressing hepatoma cells. Anticancer Drugs 22: 435443.

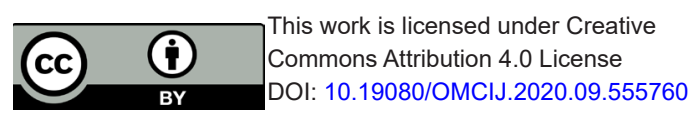

10. Mattson DM, Ahmad IM, Dayal D, Parsons AD, Aykin Burns N, et al. (2009) Cisplatin combined with zidovudine enhances cytotoxicity and oxidative stress in human head and neck cancer cells via a thiol dependent mechanism. Free Radic Biol Med 46: 232237.

11. Hengguang Li, Grace M Chavis (2018) Pseudo Aptamer Expands Aptamer's Applications. MOJ Biorg Org Chem 2(3): 145-153.

12. Venkata Ramana Sirivolua, Sanjeev Kumar V Vernekara, Tatiana Ilinab, Nataliya S Myshakinab, Michael A Parniakb, et al. (2013) Clicking 3'-azidothymidine into novel potent inhibitors of human immunodeficiency virus. J Med Chem. November 14: 56(21): 87658780 .

13. Hengguang Li, Pearson Darien (2017) Conjugates toward Medicines. J Pharmacol Med Chem 1(1): 32-39.

\section{Your next submission with Juniper Publishers will reach you the below assets}

- Quality Editorial service

- Swift Peer Review

- Reprints availability

- E-prints Service

- Manuscript Podcast for convenient understanding

- Global attainment for your research

- Manuscript accessibility in different formats

( Pdf, E-pub, Full Text, Audio)

- Unceasing customer service

Track the below URL for one-step submission https://juniperpublishers.com/online-submission.php 